\title{
PLEASE [REDACTED] MY LAST E-MAIL
}

\section{Error message.}

\section{BY KURT PANKAU}

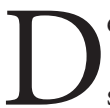
ear Laurie,

Hey. Sorry about that e-mail I sent last night. If you haven't read it yet, just go ahead and delete it. It wasn't fair of me to open up to you like that. I mean, we used to be close, but it was a long time ago and we haven't seen each other in person in over a decade and ... Look, I'd had a few glasses of wine - which isn't an excuse - and I was feeling a little vulnerable. I'm sorry.

Also, there is no robot army, and even if there was, it certainly wouldn't be marching towards [redacted].

I mean, that's just silly. Think about it. I'm a colonel in the Strategic [redacted] with numerous security clearances. All of our computers are monitored by sophisticated AI crawlers that would remove any identifying information, especially if there were any truth to it. Actually, there's a very real chance that the e-mail never reached you at all, because the monitors are so secure. Which is great - ideal, even. Because I should never have sent it. But, just in case you saw it, let me try to set the record straight. Now that the Merlot is out of my system.

First off, there's no need to leave the city. If I gave that impression, I'm sorry. Like I said, there is no robot army. If there was, it's not on its way to [redacted]. I mean, come on! Someone would have seen it by now. It'd be all over the news. Yes, yes, there are state controls on information, but things still get out. You can't move an army that size - an army that doesn't exist, I just want to stress - without it showing up on a cellphone camera or something. It would need to have some kind of highly classified [redacted] technology to cover that kind of distance undetected at speed. And that's just ridiculous, right?

But, hey, since we're talking hypotheticals here ... Even if it was heading in the general direction of, say, your very own neighbourhood, these robots - if they existed, which they don't - would be programmed to target political dissidents and minimize collateral damage. And I'm sure neither you nor Roger would be considered dissidents, even by the new expanded definitions that came out last week. Bottom line: you and your family are definitely, totally safe. Honest. ;)

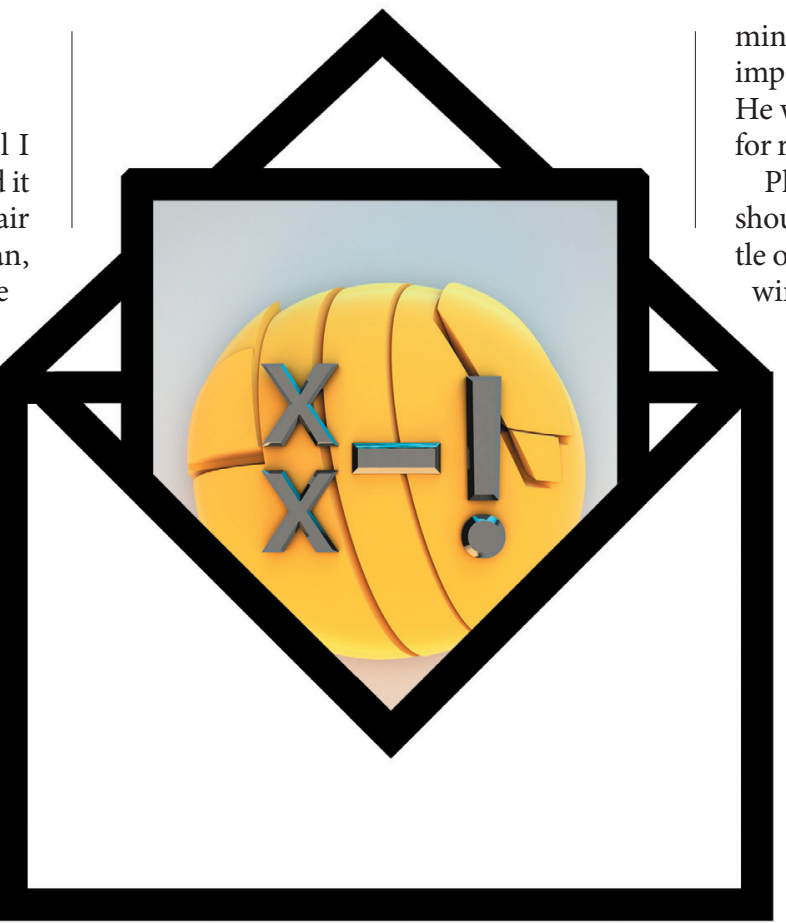

minors. This gets him in front of some very important people, who only act like fascists. He was definitely not tortured or arrested for real.

Phew. Glad to get that straightened out. I should never have opened that second bottle of wine, right? Why was I even drinking wine at the office? What would I possibly be getting drunk about? My life is great! Anyway.

So then there's the other stuff. Again, if you didn't get that e-mail, then that's probably for the best. But if you did, and if you managed to read it... Look, we're both adults. We both know what our history is - what I said and did. Was it really "the greatest regret of my life"? That may have been something of an overstatement. I mean, I absolutely, unequivocally love my son. To be clear: would I have made different choices 16 years ago if I'd known then what I know now? Absolutely. Do I regret any emotional pain I caused you? Of course I do. But any unresolved feelings I still have for
Speaking of family - Jenn is doing great, just great. She's started a new crossfit regimen that's really helping with the last of that baby weight. I keep telling her that I think she's beautiful just the way she is. I love her smile and her mind and... just the whole package really. But she's determined to get into better shape, and when she sets her mind on something, she's going to get it eventually.

Anyway, she hasn't really been kidnapped. Not really. It just feels that way sometimes, what with the demands from the kids' schools, their extracurricular activities. You know how it is.

And speaking of extracurriculars, Byron's really looking forward to baseball season. Because he still has both his arms, obviously. If I said differently in last night's e-mail, I was just being metaphorical. He's practised throwing so much that his arm has practically fallen off. That's what I meant. And the practice field only feels like a refugee camp because it's just that busy. And when I said they might be moving him to [redacted] stadium - that's a good thing. For the
ONATURE.COM Follow Futures:

\section{y @NatureFutures}

$f$ go.nature.com/mtoodm exposure, I mean. You understand. He's going to be 16 in a few months, which means he'll be eligible for the you are mine to deal with, and are the consequences of my own actions. And any heartache I may have, that's just something I have to live with. It was unfair of me to unload all of that on you.

I have a good life, even with all of what's going on in the news, and the turmoil at work, etc, etc. And so do you. I see your pictures online, and you and Roger seem genuinely happy together, and I would never, never jeopardize your happiness. I was being selfish and I'm truly sorry.

Oh, hey, one last thing. I'm definitely still alive. There's no way that I've been detained or killed and replaced by an artificial intelligence. And that's true going forward as well. Any future e-mails you get from me are also really from me. Even if they completely contradict everything I'm saying right now. Because I'm not putting myself in any danger in sending you this.

Why would I be?

Love,

[redacted] $\mathbf{\square}$

Kurt Pankau lives with his family in St Louis, Missouri. He loves board games, dad jokes and stories about time travel. He tweets at @kurtpankau and blogs at kurtpankau.com. 